\title{
Street Art: Fronteiras entre autoria e audiência na análise dialógica do documentário "Exit through the gift shop"
}

Street Art: Boundaries between authorship and audience on the dialogical analysis of the "Exit trough the gift shop" documentary

\section{João Pedro Cé \\ Pontifícia Universidade Católica do Rio Grande do Sul, Porto Alegre, RS, Brasil. Adolfo Pizzinato \\ Pontifícia Universidade Católica do Rio Grande do Sul, Porto Alegre, RS, Brasil.}

\begin{abstract}
Resumo
Este trabalho apresenta uma análise realizada sobre uma das obras de Banksy - expoente da street art contemporânea - o documentário "Exit through the gift shop". O foco do estudo, porém, está no protagonista dessa narrativa: Thierry Guetta, um imigrante francês que reside nos Estados Unidos e é proprietário de uma loja de roupas. A narrativa retrata o processo que o personagem passa, de fã a autor reconhecido no contexto da street art, gradativamente assumindo mais a identidade de Mr. Brainwash, em detrimento da identidade de Thierry. São consideradas, na análise dessa transformação, as noções de identidade, alteridade, selfdialógico e a concepção bakhtiniana de Herói. Emerge dessa análise uma noção eminentemente dialógica de construção dos personagens-chave e a relação que a própria narrativa estabelece com as possibilidades de exercício de si-mesmo em um processo que questiona as fronteiras de autor, personagem e audiência em uma proposta de reflexão sobre as possíveis construções e mutações identitárias dos sujeitos contemporâneos.
\end{abstract}

Palavras chave: Arte Urbana, Self Dialógico, Identidade, Autoria.

\begin{abstract}
This paper presents an analysis on one of the works of Banksy - exponent of contemporary street art - the documentary "Exit through the gift shop." The focus of the study, however, is the protagonist of this narrative: Thierry Guetta, a French immigrant who resides in the United States and owns a clothing store. The narrative portrays the changing process that the character lives, from a fan to a recognized author in the context of street art, gradually taking over the identity of Mr. Brainwash, rather than the identity of Thierry. Are considered in the analysis of this transformation, the concepts of identity, otherness, dialogical self and
\end{abstract}


bakhtinian notion of Hero. From this analysis emerges a notion eminently dialogical of the construction of the key character and his relationship with the narrative itself and with the possibilities of exercising oneself possibilities in a process that blurs the boundary of author, character and audience in a proposal for consideration of the possible constructions and mutations identity of contemporary subjects.

Keywords: Street Art, Dialogical Self, Identities, Autorship.

\section{Introdução}

Este artigo apresenta uma análise sobre o documentário "Exit through the gift shop" (Bansky; Cushing; D’Cruz e Gay-Rees, 2010), um filme cuja narrativa desenvolve-se sobre o movimento da Street Art (formato artístico que tem como local de apresentação e execução das imagens e esculturas os muros das cidades), focado principalmente no personagem principal cujo nome é Thierry Guetta. Esse filme é dirigido pelo artista Banksy, que também é expoente da street art na atualidade $\mathrm{e}$ amigo de Thierry. Nesta análise, acompanham-se os pontos de mudança e ressignificação identitária do protagonista, sendo que as imagens que compõem essa narrativa foram captadas durante oito anos pelo próprio Thierry, mas organizadas e editadas por Banksy, sem a participação do cinegrafista nesse processo. Além disso, as imagens reúnem depoimentos de diversas pessoas (artistas, produtores, espectadores), em cidades distintas, e jamais catalogadas. Portanto esse filme possui uma essência caleidoscópica e polifônica que é construída conjuntamente com imagens de telejornais e acervos pessoais de outros sujeitos presentes nessa história. Logo no início do filme, o próprio Banksy (diretor do longa metragem) afirma que a narrativa seria construída em cima de si próprio, porém, minutos depois afirma que "ele (Thierry) é muito mais interessante que eu”. Assim, a primeira guinada feita é na própria narrativa do documentário.

Apesar das especulações realizadas pela mídia (considerando filme como uma ficção ironizada das práticas e concepções contemporâneas sobre arte), o conceito de "documentário" pode ser utilizado como referência, já que, segundo Benet (2004), esse formato cinematográfico, apesar de seu caráter realista, possui em si uma nuance ficcional, já que há uma montagem, seleção de imagens e utilização de um roteiro, e Benet (2004) defende que nos documentários a mediação de um diretor é o que nos auxilia a apreender aquela realidade. No caso em tese, a narrativa se 
apresenta num plano de ação sociohistoricamente definido, o qual também limita as possibilidades de captação de imagens e de sentidos a serem criados pelas imagens. Portanto "a narrativa, como um discurso eminentemente temporal, assume um lugar de destaque, tanto para análise do processo de significação como de subjetividade” (Ribeiro e Lyra; 2008), subjetividade esta tanto dos protagonistas quanto daquele que nos estrutura a narrativa - Banksy.

"Exit trough the gift shop" (Bansky; Cushing; D’Cruz e Gay-Rees, 2010) possui sobre si uma atmosfera narrativa que propõe surpresas desde seu início, apresentando-se como alternativa aos documentários comuns sobre arte, onde os artistas são o foco. O eixo central do formato narrativo aqui analisado é o encontro de uma gama heterogênea de situações que culminam na exibição de um espetáculo caótico: a transmutação de um sujeito em outro. Mesmo tendo sua "veracidade" contestada, numa suspeita de que o documentário não passaria de uma "peça" pregada por Banksy em sua autopromoção (Leopold, 2010), a análise que se apresenta aqui não é acerca da apresentação da sequencialidade ou veracidade dos fatos em si, mas da organização da trama narrativa e sua relação estreita com a organização identitária do narrador e do personagem principal.

O documentário expõe como Thierry Guetta conduz a si próprio (e os registros documentais) através das lentes de uma câmera de vídeo e como essa atividade convida-o a participar e apropriar-se das atividades de um grupo, e dessa forma reconhecer outro sentido para si mesmo. Durante o desenvolvimento do documentário, outra "voz" emerge, e "voz" é entendida, aqui, como um corpus cujas elocuções afirmam posicionamentos no tempo e no espaço com idiossincrasias, participando de um contexto cultural maior, trocando e negociando opiniões com outras vozes que estão encarnadas em corpos que também têm suas particularidades, mas em conjunto expressam as condições culturais presentes naquela realidade (Bakhtin, 2008).

Dessa mudança, surge a necessidade de dirigir o olhar para os pontos (eixos) que fixam as mudanças neste "herói": os momentos em que ele considera a alteridade, e como estes "outros", contribuem para gerar rupturas no eixo discursivo original, alcançando a necessidade de expressar outra voz dentro de si mesmo, nomeada como $\mathrm{Mr}$. Brainwash (Märtsin, 2010a). É necessário entender a visão de identidade aplicada neste estudo e o que é procurado em 
Thierry/Mr. Braiwash: a tentativa de entender alteridade e diálogo como pontos de partida para outras expressões dentro de si-mesmo, ou seja, a dialogicidade dos discursos na constituição da identidade do "herói" da trama.

Como metáfora, o termo "herói" é cunhado por Bakhtin (2008) para transformar uma idéia em objeto, ou seja, conceitualizar a expressão de uma pessoa e seu posicionamento durante o cotidiano, mais especificamente, como um ser em diálogo. Assim a estrutura onde o self constrói-se não é fechada, sempre há um aspecto inconcluso, onde o outro se apresenta como testemunha, o cúmplice que completa a totalidade de um sujeito, pois seus olhos estão posicionados justamente para ver aquilo que o si-mesmo não vê: o entorno de sua perspectiva. Aquele que observa vê as fronteira que o herói não vê, seus comportamentos, o que cruza atrás de si. A totalidade estética mesclada com o contexto emerge das atividades realizadas pelo "herói”, mas é organizada pelo olhar de outrem, a troca entre personagem e autor; mesmo sendo autobiografia, "a objetificação estética $e$ ética necessita um poderoso ponto de apoio fora de si mesmo, em uma força real de onde o eu poderia ver a si mesmo como um outro" (Bahktin, 2008).
O conceito de identidade tem sido discutido em diversas disciplinas e geralmente expressa o modo como as pessoas veem a si mesmas e acabam por tomar ações influenciadas por esta visão que está baseada num sentimento de continuidade através do tempo de sua história (Brunner,1997). Segundo Tajfel (1981), a identidade no plano social tem uma dimensão que conecta ou não um sujeito a determinado grupo social e essas escolhas são baseadas nos estereótipos identificados nos grupos, e assim ele assume uma pertença a este grupo ou a outro qualquer. No caso do documentário de Banksy, em primeira instância, Thierry é apresentado como um dono de loja de roupas, um imigrante francês que vive em Los Angeles, nos Estados Unidos, desde os meados dos anos de 1980. Um comerciante que tem como característica filmar todos os momentos vividos e "jamais ir a qualquer lugar sem a câmera de vídeo”. Acima de tudo ele está capturando todo e qualquer momento: seus filhos tomando banho, sua esposa cozinhando e até mesmo os clientes de sua loja: "mesmo quando tirava fotos, ele faria como se... ele usava a câmera fotográfica como se fosse uma filmadora”, explica Débora, a esposa de Thierry.

$\mathrm{O}$ primeiro momento em que Thierry decide nunca mais perder a 
oportunidade de registrar qualquer evento de sua vida foi durante o processo de morte de sua mãe, já que perdera a vivência de um fato tão importante para si: saber da doença de sua mãe e despedir-se dela. Sua família quis protegê-lo de saber notícias sobre sua mãe e apenas o transferiu para casa de sua tia, sem explicar os motivos para Thierry, portanto, foi privado de ver sua mãe e assim ficou com a sensação de que não poderia mais perder eventos importantes. Seria então o observador da realidade que captura e tenta não perder sua totalidade, assume uma postura de constante observador e criação de si como aquele que sempre está presente, "Era uma necessidade de se capturar", como o ele próprio diz.

Com esses fatos é possível conectar à construção da identidade pessoal de Thierry o conceito de alteridade. Para Märtsin (2010a; 2010b), alteridade é um termo-chave capaz de articular aquilo que pode trazer inovação ao self, ou, em outro sentido, incitar com que aquele sentimento de continuidade proveniente da história pessoal de cada um, organizado através de uma biografia e em última instância simbolizado por uma identidade, seja aberto para mudança, porque o encontro com o "outro" e suas características particulares (a alteridade)(,) incita rupturas nesse fluxo pessoal e idiossincrático, surgindo assim a necessidade de reconstruir conscientemente os conceitos de sua própria identidade, pois cada consideração do que é diferente do "Eu" e comparada com este eu pode refutar sua própria construção e incitar outra forma de existência. Isso ocorre, uma vez que a espontaneidade do viver cotidiano, os sentidos criados e as significações presentes nesse processo são (re)negociadas com outra maneira de compreender o que está sendo vivido no aqui-agora. A alteridade não é apenas concebida como uma pessoa, ela é um ente subjetivo, as vivências cotidianas estão atravessadas por outras instâncias que estão mediando seu contato com a cultura, os grupos, instituições, e até mesmo seu passado pode ser considerado como a presença de "outro" dentro do si-mesmo (Marková, 2006). Esta mesma autora elabora a concepção de "outrointernalizado", conceito que trabalha a instância que dialoga com o "Eu" e é criada pelo si-mesmo para organizar as relações entre os sentidos do que é constitutivo do "Eu" ou do "outro".

Seguindo essa concepção de ruptura, a mesma atividade que permitia a Thierry ser autor de suas próprias memórias $\operatorname{logo}$ abriria portas para ele tornar-se "outro". Ao passar suas férias em seu país natal, a França, acaba encontrando 
seu primo no porão de casa construindo obras de arte que, posteriormente seriam expostas nos muros, ao ar livre. Esses trabalhos renderiam o codinome de "Space Invader" ao artista, pois a temática explorada nas obras remetia a um jogo de videogame dos anos 80 para a plataforma Atari®. Thierry concebe uma nova missão. Agora, "Invader" logo seria introduzido a todo um grupo e seria o observador de um movimento artístico que em sua natureza era naturalmente efêmero: a arte urbana (street art). Ele passa de um francês imigrante dono de loja de roupas e inicia um processo onde gradualmente assume uma identidade de narrador do movimento, do discurso social da arte urbana e da caracterização narrativa de seus personagens, pois tem o poder de captar cada passo dos artistas com quem entra em contato.

Através de "Space Invader", Thierry acaba conhecendo outro artista: Shepard Fairey, o qual é responsável por colar grandes cartazes pela cidade de Los Angeles, nos Estados Unidos, reunindo na mesma obra a face de um lutador dos anos 70, André “o gigante" e a palavra "OBEY". Dessa forma, Thierry aprofunda-se um pouco mais no mundo da street art e passa a ter contato com outros artistas, segui-los e assim fazer parte das intervenções, nem sempre como narrador, muitaz vezes como autor ou personagem, pois está em vigília para alertar sobre a polícia ou orientar qual o melhor lugar para que aquele cartaz seja colado ou algum desenho seja feito.

Com a câmera, Thierry é aquele que contempla a plenitude estética de seus companheiros, faz a vez e a voz do alter que coloca em evidência uma forma para aquele ser, pois, registrando os passos dos artistas, torna-se o cúmplice das atividades, é um participante que aos poucos também é construtor das intervenções urbanas, eternizando trabalhos que nascem prontos para morrer. Thierry afirma que "quando estou com os artistas, eu vivo a vida deles", e assim as filmagens tentam explicitar a trajetória e as concepções estéticas desses artistas. Assim, abre-se um canal para que a ruptura em seu cotidiano seja feita e que seu senso de identidade sofra uma reorganização, já que passa muito tempo fora de casa e loja, assumindo outras atividades que são diferentes de seu espontâneo viver do cotidiano. O depoimento de Shepard Fairey explicita a importância de Thierry na construção de suas atividades como artista: "É ótimo ter todo esse material gravado. Para mim, ter alguém de fora para vigiar, era bom (...) ele não era só o câmera, ele, de alguma forma, era o cúmplice".

As mudanças sofridas em função da alteridade podem ser profundas na 
constituição e até mesmo na apresentação do si-mesmo. Nesses momentos cria-se uma tensão no interior do indivíduo ou grupo, contribuindo para movimentos de (re)adaptação, que geram mudanças em sua totalidade - ainda que temporárias. Da mesma forma que Thierry precisa adaptar seu cotidiano ao dos artistas para filmar suas ações, ele deve se (re)apresentar nesse meio como um documentarista, um narrador, e dar um outro sentido ao documentário, já que começa a conhecer outros artistas, a gravar suas atividades, e acaba sendo questionado por estes novos personagens: "para que sãos as filmagens?". E é a partir desse desentendimento que Thierry teve a idéia de realizar um documentário, ou pelo menos justificar suas gravações com tal conceito, justificando que "realizar um documentário seria a chave para conhecer toda essa gente", numa atitude de apropriação do alter.

Assim, há posições que são colocadas em avaliação, onde o self negocia perspectivas disponíveis naquele momento, construindo a experiência e abrindo caminhos e espaços para conformidade ou inovação. Esta noção dialógica de entendimento conecta as noções de $E U$ e o Outro como interdependentes no self, entendido como instância de encontro de mútuas posições autorais de um mesmo processo de significação, onde os sentidos são partilhados através dos diálogos estabelecidos entre essas instâncias. Há uma negociação, e as considerações da alteridade geram conflitos e posicionamentos, criando, afirmando ou rompendo processos identitários, possibilitando novos posicionamentos (Marková, 2009).

A ruptura que acontece no encontro entre o que é próprio de si e do que é próprio do outro, da continuidade e da descontinuidade, é devida à negociação quando sentidos divergentes sobre os significados das experiências são colocados em diálogo, levando a reposicionamento das partes envolvidas e, portanto, modificação da sua postura original. Dessa forma, a descontinuidade torna-se fundamental para a criação de outros sentidos de identidade, ou mesmo para manutenção do que é constitutivo do sujeito, já que é necessária a relação entre as diferenças para que elas afirmem as identidades dos sujeitos em questão, onde o "eu" se reconhece e refuta o que é constitutivo do "outro", em um processo marcadamente dialógico (Märtsin, 2010a).

A definição de dialogia como processo psicossocial de constituição do simesmo e de suas relações com a alteridade emprega-se aqui através do conceito de 
Self-Dialógico proposto por Hermans (2002). De acordo com tal concepção, em cada sujeito coexiste uma noção do que é próprio de si, as características dos outros, e de qual é o cenário dialógico que possibilita a interação. Dentro dessa relação existe sempre uma temática a ser discutida e negociada e, para Hermans (2002), existem diversos pontos nesta interação dialógica, organizados dentro de um espectro, onde o compartilhamento de sentido pode ser íntimo e congruente (entre as partes que se aproximam) até distanciarse da partilha, chegando a um nível individual de organização de sentido (ainda que construído na relação com o outro $e$ assim influenciado por este contato com a outra pessoa). Assumindo que as noções de "Eu" e "Outros" só se fundamentam como unidades porque coexistem, as significações só são possíveis quando emergem das relações entre diferentes posições, percebidas como pertencentes ao exercício do si-mesmo (self), gerando os posicionamentos de "Eu" que acabam por realizar movimentações, contradições, afirmações e negociações, entendidas como sociais pela premissa dialógica, mesmo que se concebem como individuais (Hermans, 2002).

Nesse sentido, é importante analisar com mais detalhe o documentário para que se possa melhor ilustrar o processo dialógico de organização da noção de self de Thierry. Enquanto realizava suas filmagens, que duraram 8 anos, Thierry se deparava com o fato de ser pai e deixar em casa seus filhos e família e sair pelo mundo realizando filmagens: "Minha mulher estava preocupada pois havia contas a pagar e tudo o que eu queria era comprar fitas e sair por aí filmando. Eu não ficava preocupado mas eu sei que minha mulher custava a dormir algumas vezes...". Nesse ponto, Thierry não demonstra consciência de que há interferências nas noções de si mesmo que coexistem dentro de si, pois “Eu me preocupava. Pelas crianças, por todos! Ele se esquece que temos uma família e que precisamos dele", como nos diz Débora, sua esposa.

Hermans (1999) define as interações dialógicas da seguinte forma: (a) O eu e a interioridade; (b) o eu e o outro; e (c) o outro como interioridade que possui suas próprias relações. Dessa elaboração surgem espaços de interação dialógica onde os sujeitos em relação interagem discutindo e movimentando-se baseados nas possibilidades que enxergam de si mesmos, do outro e da relação que está estabelecida. Esses pontos do espectro diálogico são intersecções entre os participantes que podem ser de uma forma transparente para ser partilhada e, no outro extremo, apresentar um patamar que não é 
partilhado nem congruente com o posicionamento do outro, isto é, há patamares em que os posicionamentos não podem ser compreendidos nem vistos, pois são locais guardados na interioridade de cada um dos sujeitos e que não estão sendo expostos na relação. Dessa forma, há nessa escala níveis cujas interações têm um caráter mais unilateral, sendo a visão de cada um dos participantes sobre o outro e que não é dita, ou há partilha de algo externo à relação que pode ter a visão dos dois envolvidos. Por fim, existe a visão de um sujeito sobre o outro que pode ainda enxergar aquilo que o próprio sujeito não vê, ou enxerga de outra forma, e que é denunciado pelo outro, como, por exemplo, a relação existente em Thierry entre o "ser pai" e "ser documentarista". Há níveis que são, de certa forma, incongruentes, mas isso dentro do simesmo não é conflituoso. Porém há situações onde essas identidades são colocadas em debate, e assim emerge a discrepância entre esses papéis, como expõe o relato da esposa de Thierry transcrito acima.

A teoria do self (si-mesmo) dialógico (Hermans, 2002) defende que uma dimensão do "EU" funciona como uma sociedade, e assim o conceito de identidade é visto como algo dinâmico devido ao caráter heterogêneo das interações sociais. Essa visão permite identificar diversas vozes que contribuem para a formação do self, conforme o tempo e o espaço utilizados por aquele sujeito. É importante retomar que a voz é aquilo que torna corporificadas as elocuções de um determinado ator dentro de um diálogo, seja ele literário, real, imaginário, etc. Para a constituição da subjetividade nas interações sociais, os vários níveis de interação permitem que as posições sejam modificadas devido aos relacionamentos estabelecidos no cotidiano, e nos diálogos internos do sujeito é a imaginação e a consideração de nossa construção com influência de todas essas figuras, com suas particularidades, que resulta na elaboração da interioridade (Hermans, 1999). Todorov (2009) resume a idéia de dialogia atestando que "em lugar do absoluto, há uma multiplicidade de pontos de vista: dos personagens e do autor, sem haver privilégios ou hierarquias".

O surgimento de Banksy na vida de Thierry foi possível devido ao contato que o artista Space Invader, primo de Thierry, tinha com Banksy, pois, após terem sido apresentados e terem passados dias juntos na cidade de Los Angeles, Banksy solicitou que Thierry fosse a Londres realizar algumas gravações dos trabalhos. "Convidei Thierry para Londres porque parecia uma boa idéia começar a 
gravar as coisas. Pois era preciso, nosso trabalho desaparecia de um dia para o outro." Ninguém da equipe de Banksy estava confortável com a presença de Thierry: "Sentia que era uma falha de segurança gravar as coisas, pois ser um homem misterioso e ser filmado ao mesmo tempo parecia estúpido, é muito perigoso", diz o porta-voz de Banksy, já que todos ali sabem que suas atividades "são meio que ilegais”. Contudo, Banksy afirma: "Thierry apareceu no momento em que me dei conta de que a reação das pessoas era uma das coisas mais importantes" e, como diz Thierry, "foi então que percebi (pelas filmagens) que Banksy era como um mito”. "Posso dizer que tentei por anos esconder as coisas" - novamente, esta é a explicitação de uma mudança no processo de autoria na interioridade de Banksy.

Apesar da afirmação de que não existem níveis entre as vozes, Hermans (1999) defende a existência de diversos "outros-significativos", internalizados ou mesmo externos ao self, que têm certos pesos nas nossas decisões e influenciam nossos posicionamentos mais do que aquelas instâncias que não consideramos como importantes na nossa vida, o que revela relações de poder internalizadas influenciando no posicionamento individual. A força atribuída a uma ou outra voz depende do quanto essas transações foram realizadas durante a vida. E também de como este indivíduo considera suas alteridades (se elas são intrínsecas à formação da sua identidade de artista, público, dono de loja de roupas ou pai de família), se enfrentam a identidade e corroboram ou não os sentidos criados, como, por exemplo, o fato de Thierry iniciar também a colocar cartazes na rua e trocar sua rotina de comerciante para acompanhar as atividades de artistas. Estas avaliações são em suma embasadas no afeto direcionado a esta alteridade em questão, e organizam-se conforme a autorreflexão que o indivíduo realiza organizando seus posicionamentos de acordo com o tempo e espaço em que está inserido, variando tanto de acordo com motivos que provêm do "EU", quanto motivadas por aspectos de alteridade (Hermans, 1999).

Em consonância com essa perspectiva, o conceito de cronotopos de Mikhail Bahktin (Todorov, 2009) pode ser aplicado para nomear o ponto de encontro entre o senso de continuidade identitária do self e a descontinuidade do cotidiano, que coloca este mesmo sujeito em situações de posicionamento únicas, contextualizadas socioculturalmente. Tempo e espaço reunidos dentro do sujeito, revelando um posicionamento do "EU" frente àquela situação específica, mas orientado pela 
vivência até então experimentada de si mesmo. Esse conceito coloca a existência do Chronos, ou seja, o tempo em que acontece a ação, que reúne a história individual (com aquele momento específico vivido) em confluência com o tempo histórico micro e macrossocial. Esse tempo tem suas margens limitadas pelo Topos, o local físico que delimita a ação dentro de um campo social específico, arquitetônico, instucional, social e cultural.

Esse conceito é particularmente útil para explicar o formato que a street art estava começando a obter nos anos 2000. Banksy realizara uma exposição que atraiu a atenção da mídia e logo as peças de arte dos artistas de rua ganharam outro status, pois com "Barely Legal" o mundo do street art iniciaria a girar uma enorme quantia de dinheiro, e, como demonstra o documentário, algumas obras poderiam valer mais de 100 mil dólares, como o “orelhão vandalizado" de Banksy, vendido agora por 550 mil dólares. Porém, este mesmo artista afirma que o capital não era o foco principal do movimento, e agora era necessário que alguém trouxesse à tona toda a história destes artistas, pois suas obras contestavam a ordem do capitalismo e principalmente a lógica de propriedade privada.

Segundo o narrador "oficial" (voz em off) do documentário, era a hora de
Thierry "transformar milhares de horas de gravação jamais vistas em um épico documentário como vinha prometendo a todos há tanto tempo.". Momento propício para assumir de vez o processo de autoria e sair de trás das câmeras. Assim foi. Ou quase. Banksy questiona "que talvez Thierry não fosse um cineasta, mas um louco com uma câmera." e "seria importante fazer um filme que pudesse ser assistido e resolvi tentar. Mas como precisava de Thierry longe, disse a ele que fosse para casa e fizesse um pouco de arte. Realizasse uma exposição e convidasse alguns amigos.". O herói então seguiu os conselhos de Banksy, voltou para casa decidido a converter-se formalmente em um artista, pois possuía o aval de uma pessoa renomada do circuito, um representante de um sistema social com o poder de anunciar quem é ou não artista. Essa validação ocorre através do que Maingueneau (2008) chama de "fiador do discurso", sujeito que carrega as características em sua imagem e em seu discurso, tendo o poder de validar outro sujeito como artista. E esse processo ocorre, pois a organização do discurso e da imagem estão de acordo com aquilo que a comunidade receptora da mensagem aceita e considera como legítimo, tendo a via contrária como recíproca, já que o enunciador também cria condições para 
que seu discurso seja aceito, gerando um processo de retroalimentação das posições sociais.

\section{Entre a autoria e criação de si mesmo: processo dialógico}

Após ser o cúmplice, auxiliando a colar, filmar e vigiar, tornando-se também autor das obras de arte urbana, Thierry volta para casa e inicia a espalhar por sua cidade imagens de si mesmo segurando uma câmera. Solicitou para um amigo redesenhar e "fui até uma gráfica, conforme aprendi com "Obey" (Shepard Fairey) e comecei a fazer estas cópias de $10 \times 12$ metros. E comecei a fazer como ele, seguindo o movimento de street art.". Tal como os processos dialógicos sugeridos por Bakthin (2008), onde a incompletude é inerente à criação de si como personagem de uma história, Therry inicia então outra atividade, diretamente influenciado pelas práticas de um grupo do qual antes era observador. Nessa interação ele alcança o local de protagonista, assume sua própria voz, incitada por outras vozes.

Essa passagem também nos coloca a questão que Bakhtin (2008) chama de ventriloquismo, conceito que traduz como as vozes coletivas estão entremeadas no discurso dos grupos sociais e como esses grupos se manifestam nos discursos individuais, processo conceituado também como polifonia ou heteroglossia. As vozes não são entendidas como sobrepostas, mas como entrelaçamentos, pois tropeçam, negociam e criam o próprio coro das vozes, jogando com as diversas tonalidades, melodias e tempos, consagrando campos "inarmônicos". Quando Banksy diz que, em relação à técnica "Não há ninguém como ele (Therry), ainda que sua arte pareça como a de qualquer um de nós", temos um exemplo significativo desta interação intersubjetiva.

Há, portanto, vozes coletivas, e cada uma das vozes dos indivíduos dentro do grupo, com diferentes graus de apego à voz coletiva ou à voz de si mesmo, ou ainda do outro dentro do grupo, que vão sofrendo mútuas influências, para afirmarem-se ou mudarem. Desse modo, os opostos criam as dicotomias que acabam por revelar diferenças de poder entre as vozes. Como uma possui o que a outra não tem, acaba por sobrepujar os posicionamentos restantes, não havendo uma verdadeira liberdade de expressão, e o enfrentamento de diferentes posições impossibilitando o entendimento dos microdiálogos fora do contexto cultural maior (Marková, 2009; 2006). Nesse sentido, "Exit through the gift shop" nos mostra que valores altíssimos cobrados 
pelas obras e exposições lotadas de espectadores juntamente com o apoio midiático formam elocuções que podem legitimar o sucesso dos exercícios da arte na cultura ocidental.

A missão de organizar uma exposição de arte foi concebida por Thierry a pedido de Banksy para fazer "um pouco de arte, abrir umas garrafas de vinho e convidar uns amigos para assistir". Então Thierry expressa que começou seu trabalho em relação ao que Banksy já fizera, pois havia um respeito sobre o trabalho de seu "mestre". Contudo a exposição só pôde ser realizada com a criação de Mr. Brainwash (MBW). Thierry conceitua que "todo movimento artítico consiste em lavaem cerebral, Obey consiste em lavagem cerebral, Banksy consiste em lavagem cerebral. Foi então que eu me tornei o Mr. Brainwash.”. Considera-se, nessa passagem, mais uma vez, o conceito de dialogia e conhecimento social (Marková, 2006) na formação de um conceito tal como o de arte, e especificamente na elaboração de uma identidade a partir de um movimento social e de alter-egos "outros" - dentro deste movimento. Surge no entremeio dessas diversas vozes outro personagem - Mr. Brainwash.

Seis meses após a exposição, Thierry havia vendido sua loja de roupas e investido todo o seu dinheiro em aparatos como serigrafias, impressoras, tintas, papéis e contratado uma equipe para realizar todos os projetos de MBW. "Como Damien Hirst, que tem uma equipe de 100 pessoas. Tu achas que ele vai cortar papéis? Eu quero chegar com a ideia e mandar: é isso que eu quero, e quero isto deste jeito." Dessa forma, o híbrido personagem vai exercendo sua autoria, em conjunto com outros, baseado em outros, apoiado e protagonizando um grupo, até culminar em sua exposição de arte, chamada "Life is beautiful".

Para realização de sua exposição Thierry/MBW ainda necessita que outros apóiem sua realização. Sozinho, parece que este personagem perde força e por isso usa a força de personagens renomados do meio artístico, tais como Banksy e Shepard Fairey, que foram solicitados para dar depoimentos sobre o que seria "Life is beautiful". Voltando à concepção de inner alter de Marková (2006) e do outro singificativo de Hermans (1999), estes personagens que influenciam também as opiniões, ações e em suma a expressão de si mesmo. Thierry/MBW personagem fala sobre um dos motes de realizar sua exposição em um local abandonado, mas que fosse gigante e no meio da cidade de Los Angeles: "Eu não queria desapontar 
Banksy, queria tentar algo grandioso"; e, como traz a voz do narrador do documentário, "Thierry, teria emulado a exposição que Banksy fizera em L.A", pois um dos produtores de sua exposição salienta que "já havia visto muitas exposições pelo mundo todo, de pessoas e ele (Thierry) pensou: 'quero fazer algo tão bacana quanto". A última tarefa que iria consagrar MBW, sua exposição, necessitava ainda de um trabalho publicitário. Nisto, haveria duas pessoaschave para que o trabalho fosse atestado como notório no meio artístico: Shepard e Banksy. Com declarações desses dois artistas, a mídia inicia a buscar entrevistas com Mr. Brainwash, o que alavanca o status das atividades desta nova identidade de Thierry. O sucesso de "Life is beautiful" foi também medido em números. Em sua estreia, duas mil pessoas estavam esperando a abertura da exposição e em uma semana havia faturado uma quantia superior a um milhão de dólares.

Finaliza-se aí a criação mitológica de um artista contemporâneo.

\section{Considerações finais}

Os eventos perdem o sentido de eventualidade devido aos significados que o si-mesmo cria nessas experiências, e estas estão intrinsecamente minadas pela relação com a alteridade. Em uma perspectiva bakhtiniana é afirmado que a experiência de identidade é uma autocriação de si-mesmo, que considera seus próprios valores, construídos naquela cultura e contexto, e a visão que se tem de si mesmo nessa trama (Bakhtin, 2008). É a incorporação de um diálogo imaginado, porém vivido na estória da pessoal real (Faraco, 2009).

Entende-se que a alteridade e as rupturas no cotidiano realizam estas guinadas na concepção de si, alavancando buscas de outras identidades pessoais e consequentemente sociais, mas essas mudanças muitas vezes só são vistas ao fim, e não durante o processo de transformação.

Se há verdade ou não na narrativa analisada, não cabe aqui definir. Porém existe uma questão que alimenta discussões. É fato que nos importa menos o quanto de verdade foi dita, é mais o entendimento da forma de narrativa cotidiana. Como em um documentário, na constituição do "EU" também há montagem para dar-se coerência ao que é dito. Assim como a própria história individual de cada um, que omite, transforma e inventa elementos, para ser coerente não com o fato em si, mas com algo maior, sua própria identidade e a 
identidade de Banksy é a do sujeito zombeteiro, que nos impõe a dúvida do irreal e do real. A única certeza que gera é a da materialidade irreal produzida por qualquer tipo de narrativa.

\section{Referencias}

Bakhtin, M. (2008). Estética de la creación verbal. Buenos Aires: Siglo XXI.

Bakhtin, M. (2008). Cultura popular na idade média e no renascimento: o contexto de François Rebelais. São Paulo: Hucitec.

Banksy; Cushing, H.; D’Cruz, J. \& GayRees, J. (2010) Exit trough the gift shop [Filme - Documentário]. Banksy, Dir., H. Cushing, J. D’Cruz, J. Gay-Rees, Prod. United Kingdom: Paranoid Pictures. 1 DVD, 87 min. Color. Son.

Benet,V. J. (2004). La cultura del cine: introduction a la historia y la estetica del Cine. Barcelona: Ediciones Paidós.

Brunner, J. S. (1997). Atos de significação. Porto Alegre: Artes Médicas.

Faraco, C. A (2009). Autor e Autoria. Em Brait, B. (org.) Bakhtin: conceitoschave (pp.37-60). São Paulo: Contexto.
Hermans H.J.M. (1999). Dialogical thinking and self innovation. Culture \& Psychology. 67(5), 67-87.

Hermans, H.J.M. (2002). The dialogical self as a society of mind .Theory \& Psychology, 2 (12), 147-160 .

Maingueneau (2008), Cenas de Enunciação. São Paulo: Parábola.

Marková, I. (2006). Dialogia e representações sociais as dinâmicas da mente. Petrópolis: Vozes.

Marková, I. (2009). On the "Inner Alter" in dialogue. International Journal of Dialogical Science 1(1), 125-147.

Märtsin, M. (2010a). a identity in dialogue: identity as hiper-generalized personal sense. Theory Psychology, 20(3), 436-450.

Märstin, M. (2010b). Commentary: making sense of identity dialogues. Culture \& Psychology, 16(1), 109-115.

Ribeiro, A. K \& Lyra, M.C.D.P (2008). O processo de significação no tempo narrativo: uma proposta metodológica. Estudos de Psicologia, 14(1), 65-73.

Leopold, S. (2010). Banksy Revealed? L.A. Weekly. Recuperado em 17 de setembro , 2012, de http://www.laweekly.com/2010-0408/art-books/banksy-revealed/. 
Tajfel, H. (1981). Human groups and social categories. Cambridge: Cambridge University Press

Todorov, T. (2009). La crítica de la crítica. Barcelona: Paidós.

$\overline{\text { João Pedro Cé está concluindo o curso de }}$ graduação em Psicologia, foi bolsista do Programa de Educação para o Trabalho em Saúde da Família e atualmente é Bolsista do Grupo de Pesquisa Identidades, Narrativas e Comunidades de Prática e Estagiário do Centro de Referência em Assistência Social - Cruzeiro.

E-mail: joaopedroce@yahoo.com.br

Adolfo Pizzinato é Psicólogo, Doutor em Psicologia pela Universidade Autônoma de Barcelona. Atualmente é Professor do Programa de Pós-Graduação em Psicologia na área de concentração da Psicologia Social e é Coordenador do Grupo de Pesquisa Identidades, Narrativas e Comunidades de Prática.

E-mail: adolfo.pizzinato.@pucrs.br 